\title{
Automatic generation control of multi source interconnected power system using adaptive neuro-fuzzy inference system
}

\author{
Deepesh Sharma \\ Department of Electrical Engineering, DCR University of Science \& Technology, Murthal, Sonepat, INDIA \\ "Corresponding Author: e-mail: deepesharma327@gmail.com,Tel +91-9812840554 \\ ORCID iD: https://orcid.org/0000-0002-4787-1415
}

\begin{abstract}
LFC (Load Frequency Control) difficulty is created by load of power system variations. Extreme acceptable frequency distinction is $\pm 0.5 \mathrm{~Hz}$ which is extremely intolerable. Here, LFC is observed by PID controller (PID-C), Fuzzy and ANFIS controller (ANFIS-C). To control different errors like frequency and area control error (ACE) in spite of occurrences of load disturbance and uncertainties of system is checked by MATLAB/SIMULINK software. Proposed Controller offers less, and small peak undershoot, speedy response to make final steady state. LFC is mandatory for reliability of large interconnected power system. LFC is used to regulate power output of generator within specified area to maintain system frequency and power interchange. Here, two area multi source LFC system is analyzed. ANFIS is utilized for tie-line power deviation and controlling frequency. Proposed controller is compared with other controller and it is found that proposed controller is better than other controller. Proposed controller is better in terms of Robustness. The output responses of interconnected areas have been compared on basis of peak-undershoot, peak-overshoot and settling time $\left(\mathrm{T}_{\mathrm{S}}\right)$. Result of FLC is compared to that of with classical controller such as proportional derivative plus integral (PID) controller which suggests that conventional controller is slow.
\end{abstract}

Keywords: LFC, Fuzzy, PID, ANFIS, LFC; FLC; ACE; PID-C, AGC.

DOI: http://dx.doi.org/10.4314/ijest.v12i3.7

Cite this article as:

Sharma D. 2020. Automatic generation control of multi source interconnected power system using adaptive neuro-fuzzy inference system. International Journal of Engineering, Science and Technology, Vol. 12, No. 3, pp. 66-80. doi: 10.4314/ijest.v12i3.7

Received: June 11, 2020; Accepted: June 28, 2020; Final acceptance in revised form: August 27, 2020

\section{Introduction}

The goal of LFC is to keep up planned frequency and tie-line control in ordinary method of activity, during little irritation in working conditions. It keeps up generator-request of region in endorsed limit by modifying senator yield as explained by Zribi et al. (2015), Shayeghi and Shayanfar (2006). Large interconnected power frameworks are made out of control territories or districts, speaking to lucid gathering of generators. Various regions are associated through tie-lines. Tie-lines are used for trading vitality between back to back two-territories and gives between territory support if there should arise an occurrence of anomalous states of intensity framework as described by Kocaarslan and Cam (2005). On event of burden change, bungle in frequency and booked power trade between zones happens in framework. This jumble must be adjusted by LFC, which is characterized as guideline of intensity yield of generators inside middle of as far as possible as mentioned by Khodabakhshian and Golbon (2005), Sharma and Yadav $(2017,2018)$. Number of regular controller like PID, PI, I are utilized in charge framework, as this controller is easy to execute, straightforward and having minimal effort. Nature of their control system is dependable and announced as hearty for some 
working conditions. Many control strategies have been accounted for writing to control frequency and tie-Line control in LFC framework like adaptive neuro fuzzy inference system (ANFIS), NARMAL-2 controller, and so forth as explained by Stankovic et al. (1998), Sharma and Yadav (2019), and Sharma (2020).

\section{Literature Review}

Numerous analysts have utilized customary controller and ideal PID-C for controlling frequency deviation and Tie-Line control. In this paper single and twofold zone LFC is intended for frequency and power deviation control as described by Melin and Castillo (2003) and Sepulveda et al. (2005). Proposed fuzzy rationale gives preferable outcomes over traditional controller like PID; smart controller results are contrasted and old style controller Using MATLAB programming. Control deviation and frequency reaction acquired by FLC in LFC are contrasted and LFC having PID-C as far as Ts, rise time and pinnacle overshoot. Nanda and Mangal (2004) have proposed work on FLC for automatic generation control of hydro-thermal plant system and results have been compared that of with PI controller as presented by Shayeghi and Shayanfar (2006). Robust FLC for uncertain nonlinear power system have been presented by Hameed et al. (2010). Yesil et al (2004) have proposed self-tuning fuzzy PID type controller for LFC problem and its result compare with conventional controller. Sahu et al. (2015) have presented LFC for two area non-reheat turbine system and PID-C parameters were optimized using teaching learning based optimization technique. Ikhe (2013) have considered LFC using PID, PI, I controllers and compared results. Recently, Application of particle swarm optimization to FLC have been presented for LFC in smart grid. FLC and fuzzy knowledge-based decision systems are well presented by Panda et al. (2009). Number of rules increases exponentially with number of variables for FLC applications to large and complex systems. Hierarchical fuzzy systems are one of alternatives to reduce number of rules as presented by Usman and Divakar (2012). In 2019, Sharma and Yadav was mainly concerned with representing the LFC for Two-area interconnected power system that comprised of thermal, hydro and gas. In this research an optimal design of FOPI controller using lion with levy update was presented. Sharma and Yadav (2020) have proposed the LFC for Two-area interconnected power system that comprised of three sources i.e. thermal, hydro and gas. In this research an optimal design of FOPI controller was presented.

\section{System for LFC}

The reason of frequency drop is that prime mover slows down to compensate for imbalance in power; however, speed is controlled by power generation. As speed change lessens; mistake sign decreases, and senator speed is made consistent. Be that as it may, it is difficult to fix senator speed to set point since burden is fluctuating with time; in this manner, we use control framework with integrator. Control system examinations change and make redresses likewise to expel balances. Capacity of framework to return to its ordinary worth is named as reset point. Accordingly, AGC is plot which reestablishes frequency to its ostensible worth naturally. In Figure 1 AGC for single region is appeared, AGC comprise of representative framework which gives sign to turbine to change its speed to keep up frequency consistent.

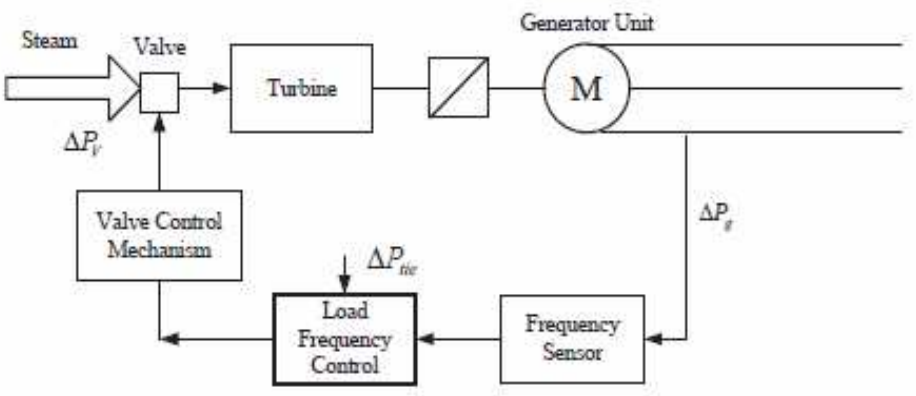

Figure 1. Block diagram of automatic LFC

\subsection{Modeling of single area system}

The principle parts of framework comprise of Governor, prime mover burden and latency model. These are portrayed as following:

Governor model: $\Delta \mathrm{Pg}$ is changed by pressure driven speaker to steam valve position $\Delta \mathrm{Pv}$. $\mathrm{Tg}$ is senator time consistent, move capacity of representative is given in Eqn.1.

$$
\frac{\Delta P_{v}(s)}{\Delta P_{g}(s)}=\frac{1}{1+T_{g} s}
$$


Prime mover model: It is utilized for delivering mechanical power; it might be steam for steam turbine, water divider for pressure driven turbine. model of prime mover $\Delta \mathrm{P}_{\mathrm{m}}$ relates mechanical power yield to change in steam valve $\Delta \mathrm{P}_{\mathrm{v}}$ worth exchange capacity is given in Eqn.2

$$
\frac{\Delta P_{m}(s)}{\Delta P_{v}(s)}=\frac{1}{1+T_{t} s}
$$

Load and inertia model: It is touchy to frequency change and can be investigated by speed load trademark as given in Eqn. 3.

$$
\frac{\Delta \omega(s)}{\Delta P_{m}-\Delta P_{i}}=\frac{1}{2 H+D}
$$

Frequency bias factor: It is total of frequency delicate burden change (D) and speed guideline as given in Eqn. 4.

$$
B=\frac{1}{R}+D
$$

System can be exhibited utilizing Eqn.1. to Eqn.4. (Figure 2).

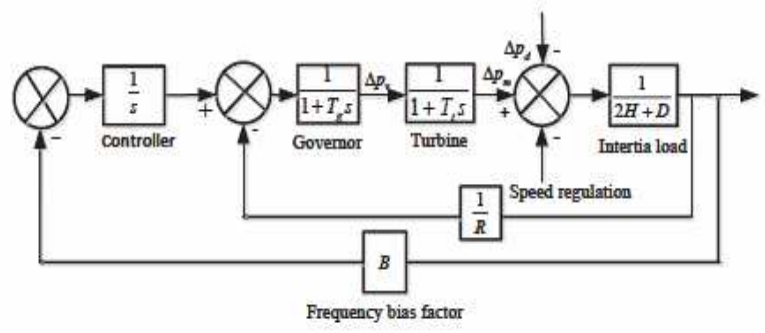

Figure 2. Block diagram of LFC for single zone framework

3.2 Modeling of two-area system

A two-region framework is spoken to by identical producing unit interconnected by lossless tie line with reactance of Xtie in Figure 3.

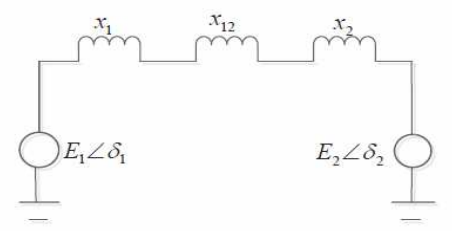

Figure 3. Representation of two-area system

The genuine power moved over tie-line during typical working conditions is given below by Eqn.5.

$$
P_{12}=\frac{\left|E_{1} \| E_{2}\right|}{X_{12}} \sin \Delta \delta_{12}
$$

Consider little deviation of rotor edge _0 coming about tie line control $\Delta \mathrm{P}_{12}$ is given below by Eqn.6.

$$
\Delta P_{12}=\frac{\theta P_{12}}{\theta \delta_{12}}
$$

The synchronous power coefficient is given below by Eqn.7. 


$$
P_{s}=\frac{\left|E_{1} \| E_{2}\right|}{X_{12}} \cos \Delta \delta_{12}
$$

Considering burden change $\Delta \mathrm{PL} 1$ in territory 1 at time of enduring state in frequency. It results as $\Delta \mathrm{w}=\Delta \mathrm{w}_{1}=\Delta \mathrm{w}_{2}$.

$$
\begin{aligned}
& \Delta P_{m 1}-\Delta P_{m 2}-\Delta P_{i 1}=\Delta \omega D_{1} \\
& \Delta P_{m 2}+\Delta P_{i 2}=\Delta \omega D_{2}
\end{aligned}
$$

The change in mechanical power is dictated by utilizing senator speed trademark and is given as below

$$
\begin{gathered}
\Delta P_{m 1}=\frac{-\Delta \omega}{R_{1}} \\
\Delta P_{m 2}=\frac{-\Delta \omega}{R_{2}} \\
\Delta \omega=\frac{-\Delta P_{i 1}}{B_{1}+B_{2}} \\
\Delta P_{12}=\frac{B_{2}}{B_{1}+B_{2}}\left(-\Delta P_{i 1}\right)
\end{gathered}
$$

3.3 Tie-line bias control

It is utilized to keep up frequency and power at pre-indicated esteem where in every zone deals with its own heap. traditional LFC depends on tie line inclination control; in which every region is attempting to diminish blunder to zero. Expert is given by

$$
\begin{aligned}
& A C E_{1}=\Delta P_{12}+B_{1} \Delta \omega_{1} \\
& A C E_{2}=\Delta P_{21}+B_{2} \Delta \omega_{2}
\end{aligned}
$$

By utilizing above Equations, square outline can be made as given beneath of two territory interconnected power framework is appeared in Figure 4.

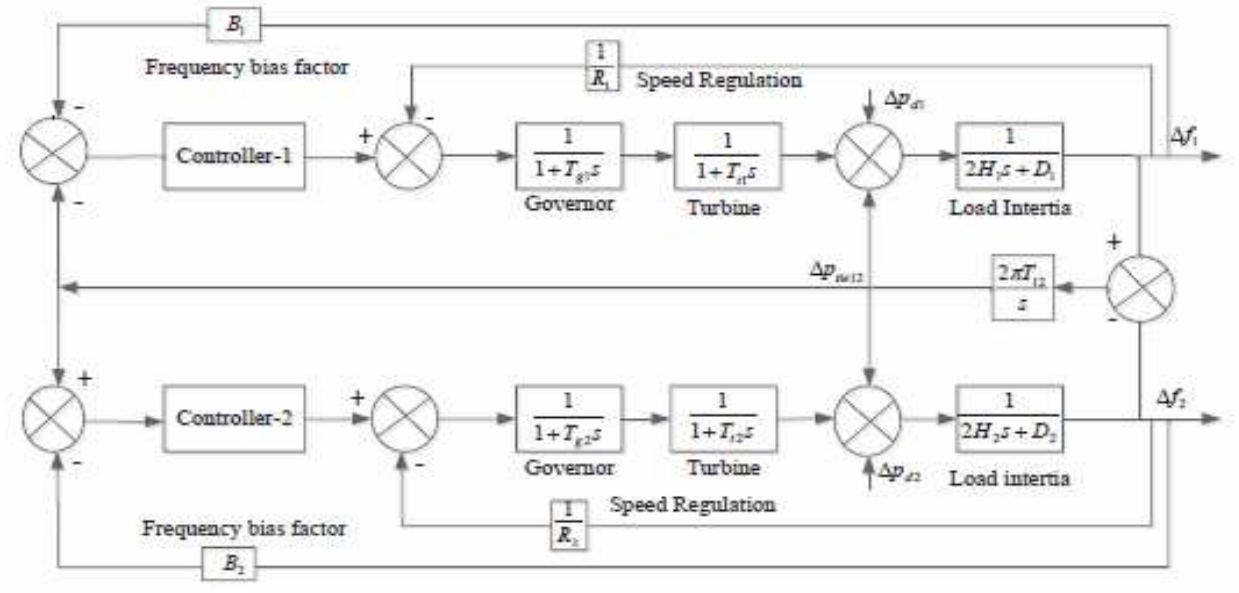

Figure 4. Block diagram of two-area interconnected system

In this paper, single region framework and interconnected power framework with two-territories have thought about. framework model comprises of representative, non-warm turbine and burden dormancy in exchange capacity structure and speed guideline consistent and frequency predisposition factor are input to frequency yield, there is frequency deviation in separated framework given as $\Delta \mathrm{f}$, in two territory framework are two frequency deviation $\Delta \mathrm{f} 1$ for region 1 and $\Delta \mathrm{f} 2$ for zone 2 . Power request increase for territory 1 is $\Delta \mathrm{P} 11$ and for region 2 is $\Delta \mathrm{Pl} 2$, this power request is given in step burden structure. FLC is utilized for controlling frequency and power deviation in single and two are framework. Structured FLC has forty nine principles and seven participation capacities are utilized for each info and yield. triangular enrollment capacity is utilized for controller and centroid strategy is utilized for defuzzification as mentioned by Panda et al. (2009). 


\section{Proposed Controller}

\subsection{PID-C}

The PID-C is by a wide margin most normal control calculation. Most down to earth criticism circles depend on PID control or some minor varieties of it. Numerous controllers don't utilize subsidiary activity. PID-Cs shown up in a wide range of structures, as remain solitary controllers, they can likewise be a piece of DDC (Direct Digital Control) bundle or various leveled dispersed procedure control framework or they are incorporated with implanted frameworks. PID calculation can be drawn closer from a wide range of bearings.

This segment offers prologue to PID control. Essential calculation and different portrayals are displayed in detail. Portrayal of properties of controller in shut circle dependent on instinctive contentions is given. Wonder of reset windup, which happens when controller with vital activity is associated with procedure with soaking actuator, is examined, including a few strategies to keep away from it. Channels to lessen clamor impact and intends to improve reference reactions are likewise given.

The textbook version of PID-C is

$$
u(t)=k e(t)+k_{i} \int_{0}^{t} e(\tau) d \tau+k_{d} \frac{d e}{d t}
$$

Where $\mathrm{u}$ is control sign and $\mathrm{e}$ is control blunder $(\mathrm{e}=\mathrm{r} ; \mathrm{y})$. Reference worth is additionally called set point. Control sign is therefore total of three terms: P-term, I-term and D-term is relative to blunder, to essential of mistake and to subordinate of mistake, individually. Controller parameters are corresponding increase $\mathrm{k}$, indispensable addition $\mathrm{k}_{\mathrm{i}}$ and subordinate addition $\mathrm{k}_{\mathrm{d}}$. Controller can likewise be parameterized as

$$
u(t)=k\left(e(t)+\frac{1}{T_{i}} \int_{0}^{t} e(\tau) d \tau+T_{d} \frac{d e(t)}{d t}\right)
$$

where $T_{i}$ is called integral time and $T d$ is derivative time.

\subsection{FLC}

The FLC depends on fluffy rationale and gives calculation which changes over phonetic control technique dependent on master information into programmed control methodology as described by Hameed et al. (2010). By complex control method it is hard to examine complex issues (Bhatt et al., 2010). FLC are chiefly helpful, at whatever point wellspring of data is unsure or not correct as mentioned by Kothari et al. (1989). It comprise of four segments, diverse piece of fluffy control is given in Figure 1.

\subsection{Adaptive neuro fuzzy inference scheme}

It utilizes semantic terms in addition to structure of IF-THEN principles. Differentiating neural systems idea, fluffy rationale independent from anyone else cannot learn. Learning in addition to distinguishing proof of fluffy rationale frameworks require embracing strategies from zones like measurements and framework recognizable proof. As neural systems can adapt in this way it is normal to join these two strategies. This consolidated strategy for learning intensity of NNs with information portrayal of FL has grown new crossover procedure, named as 'neuro fluffy systems'. This ANFIS approach is increasingly productive. Guidelines are in semantic sorts accordingly halfway outcomes can be effectively inspected and translated. Modification of guidelines is likely during preparing with improvement should be possible by hand. Also ANFIS approach underpins TS based strategies. To start ANFIS adapting, first, preparing informational collection that incorporates favored information/yield information sets of objective frameworks to be displayed is required. Improvement parameters mandatory for any ANFIS-C are as per the following:

- Number of information sets,

- Preparing informational collection and checking informational collections,

- Fluffy surmising frameworks for preparing,

- Number of ages to be picked to begin preparing,

- $\quad$ Learning results to be checked in the wake of referencing step size.

In this foundation, generally useful ANFIS control structure calculation to direct any plant is as per the following. This game plan incorporates same parts as FIS, other than for NN square. Structure of system is comprised of set of units in addition to associations prearranged into five related system layers, i.e., layer 1 to layer 5 (Figure 5).

Layer 1: $\quad$ This layer incorporates input factors called enrollment capacities for example input 1 and info 2.

Presently, triangular or else ringer molded MF might be utilized. This layer just supplies input norms xi to along these lines layer, where $\mathrm{I}=1$ to $\mathrm{n}$.

Layer 2: $\quad$ This layer named as enrollment layer confirms for loads of each mf. It acquires info esteems xi from first layer in addition to go about as MFs to speak to fluffy arrangements of relating input factors. More, it figures participation esteems that determine degree to which info esteem xi fits in fluffy set to contributions of next layer. 
Layer 3: This layer is named as standard layer. Every hub or neuron in this layer executes pre-condition coordinating of fluffy principles. They compute enactment level of each standard and number of layers being indistinguishable from number of fluffy principles. Every hub of these layers ascertains loads to be standardized.

Layer 4: $\quad$ This layer is named as defuzzification layer. It gives yield esteems y coming about utilizing induction of principles. Relationship among layers 13 and 14 are weighted by fluffy singletons. It symbolizes another arrangement of parameters for neuro fluffy frameworks.

Layer 5: This layer is named as yield layer. Entirety of all data sources got from layer 4 with changes fluffy arrangement closes into fresh for example parallel.

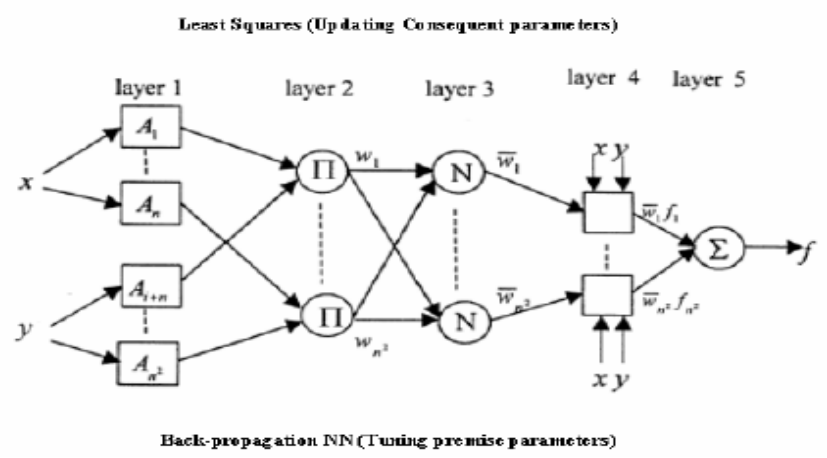

Figure 5. Developed adaptive neuro FLC design

The ANFIS game plan is tuned mechanically by least-square-estimation with back proliferation calculation. The above indicated calculation is utilized in next part to create ANFIS-C to control different parameters of acceptance engine. In light of its adaptability, ANFIS approach can be utilized for wide scope of control purposes.

\subsection{Design of ANFIS-C}

An ANFIS-C is apparatus that controls every single activity in framework to decide. From control framework perspective, ANFIS$\mathrm{C}$ is carrying steadiness to framework when there is irritation thus defending gear from further repayment. It might be equipment or programming or blend of both based controller. In this fragment, structure of control system for control of assorted parameters of DFIG is speed, motion, torque, voltage and current. These are introduced by ideas of ANFIS control conspire in type of square outline and are appeared in Figure 6.

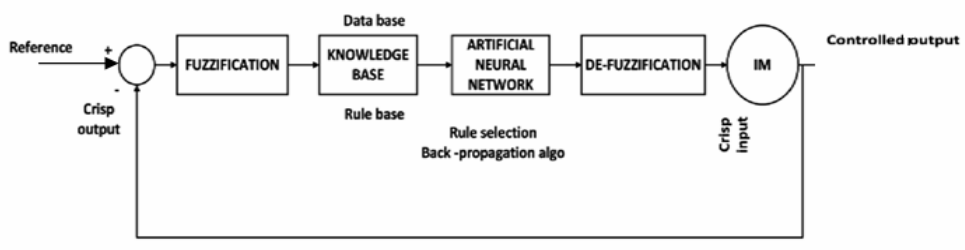

Figure 6. Block diagram of ANFIS control scheme

In the first place, we create controller utilizing ANFIS technique. Fluffy rationale is one of valuable uses of fluffy set. Factors are phonetic not numeric factors. Semantic factors are characterized in characteristic language, (for example, huge or little) with fluffy sets. Fluffy set is expansion of 'fresh' set where component can just have a place with set or not have a place by any stretch of the imagination. Fluffy sets license incomplete enrollment. It implies that component may mostly have a place with more than one set. Fluffy arrangement of universe of talk $\mathrm{X}$ is relate to by aggregation of requested sets of conventional fixing and its enrollment

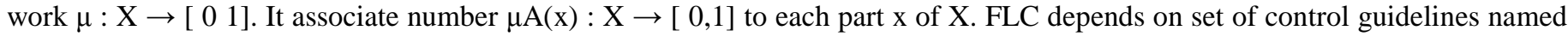
as fluffy standards among etymological factors. These principles are expressed in utilizing restrictive proclamations. Our essential association of created ANFIS coordination controller is to control speed. IM incorporates four significant parts, to be specific, Fuzzification, information base, neural system in addition to de-fuzzification squares. Commitments to ANFIS-C are mistake and change in blunder is displayed in Eq. 8 and 9

$$
\begin{aligned}
& e(k)=\omega_{r e f}-\omega_{r} \\
& e(k)=e(k)-e(k-1)
\end{aligned}
$$

Here, $\omega_{r e f}=$ the reference speed, $\omega_{r}=$ the actual rotor speed, $e(k)=$ error and $\Delta e(k)=$ change in error 
The fuzzification unit changes fresh information into semantic factors to offer contributions to lead based square. Set of forty nine principles are given on premise of past information in standard based unit. Standard base unit is related to neural system unit. Back engendering calculation is utilized to prepare neural system to pick proper arrangement of principle base. For creating control signal, preparing is significant advance in decision of proper guideline base. When legitimate principles are picked and terminated at that point control sign expected to get ideal yields is created.

The yield of NN unit is given as contribution to de-fuzzification part and semantic factors are changed again into numeric sort of information in fresh kind. In fuzzification process, fresh factors, speed deficiency and change in blunder are changed into fluffy factors or else phonetics factors. Fuzzification plans two info factors to semantic marks by fluffy sets. Fluffy composed controller utilized phonetic names. Each fluffy name has associated enrollment work. Participation capacity of triangular kind is utilized in displayed work. Data sources are fuzzified by fluffy sets and afterward are provided as contribution to ANFIS-C. Principle base for decision of right standards utilizing back spread calculation is given in Table 1.

The planned fluffy principles (7×7) are grasped in ANFIS-C and are not given here. Control choices are proposed on premise of fuzzified factors of Table 1 induction draws in set of standards for designing yield choices. Proposed ANFIS-C has two info factors, seven fuzzified factors and set of forty nine principles. Out of these forty principles, suitable guidelines are picked via preparing of neural system utilizing help of back engendering calculation at that point picked standards are terminated. Also, it must be changed into numerical yield for de-fuzzification.

Table 1. Rules for controlling

\begin{tabular}{|l|l|l|l|l|l|l|l|}
\hline E & NB & NM & NS & ZE & PS & PM & PB \\
\hline NB & NB & NB & NB & NB & NB & NM & NS \\
\hline NM & NB & NB & NM & NM & NS & ZE & PS \\
\hline NS & NB & NM & NS & NS & ZE & PS & PM \\
\hline ZE & NB & NM & NS & ZE & PS & PM & PB \\
\hline PS & NM & NS & ZE & PS & PS & PM & PB \\
\hline PM & NS & ZE & PS & PM & PM & PB & PB \\
\hline PB & ZE & PS & PM & PB & PB & PB & PB \\
\hline
\end{tabular}

This de-fuzzification is process of producing quantifiable result in fuzzy systems. defuzzifcation changes fuzzy set information in numeric data information.

\section{Proposed System Design}

Basically 3 designs are proposed for performance analysis of LFC. These are LFC controlled by PID-C, LFC controlled by Fuzzy and LFC controlled by ANFIS.

\section{PID-C}

In LFC, PID is design so that it is controlled all transfer function. Two arrangements are given for different area like area-1 and area -2 respectively (Figure 7). PID-C is replaced by tilted proportional action in PID-C, having transfer function $1 / s^{n}$ or $\mathrm{s}^{-1 / n}$. The structure of PID-C is combined with FLC as shown in Figure 8.

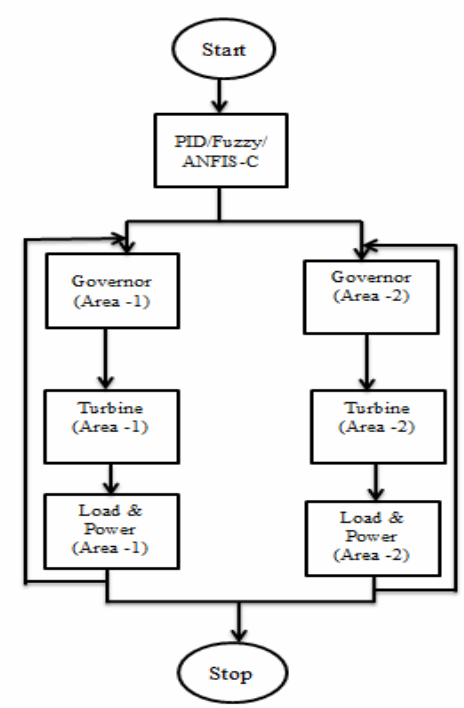

Figure 7. Flow Chart of LFC using PID, Fuzzy \& ANFIS-C 


\section{Proposed Algorithm}

7.1 FLC

In LFC, Fuzzy is design so that it is controlled all transfer function. Two arrangements are given for different area like area- 1 and area -2 respectively. Tilt integral derivative control is feedback control that is similar to FLC and also possesses merits of FLC having transfer function $1 / s^{n}$ or s $^{-1 / n}$. Structure of FLC with LFC is shown in Figure 8.

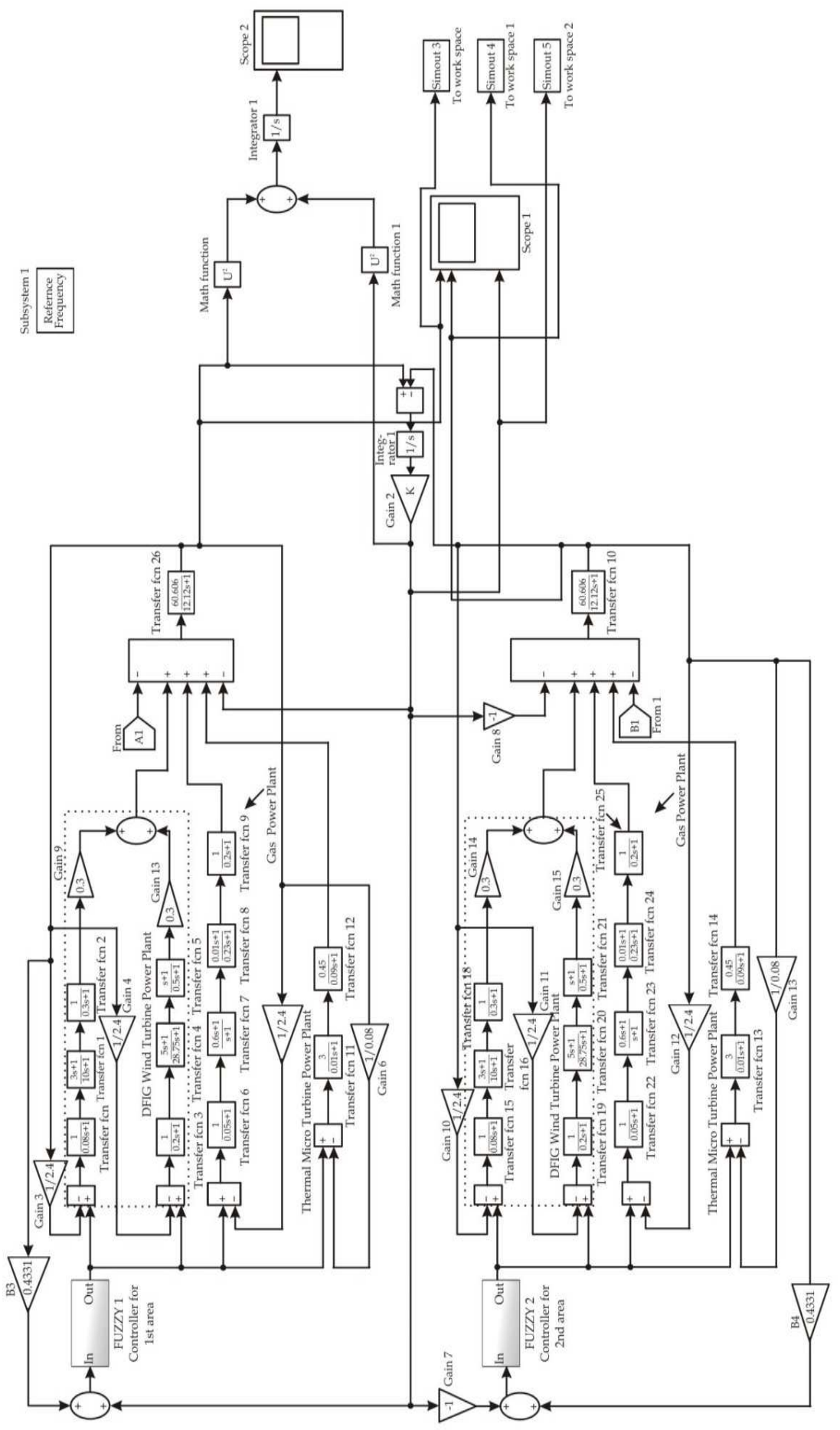

Figure 8. LFC using FLC 
In LFC, ANFIS is design so that it is controlled all transfer function. Two arrangements are given for different area like area- 1 and area -2 respectively. Tilt integral derivative control is feedback control that is similar to ANFIS control and also possesses merits of PID-C having transfer function $1 / s^{n}$ or s $^{-1 / n}$. Structure of ANFIS control system with LFC is demonstrated in Figure 9.

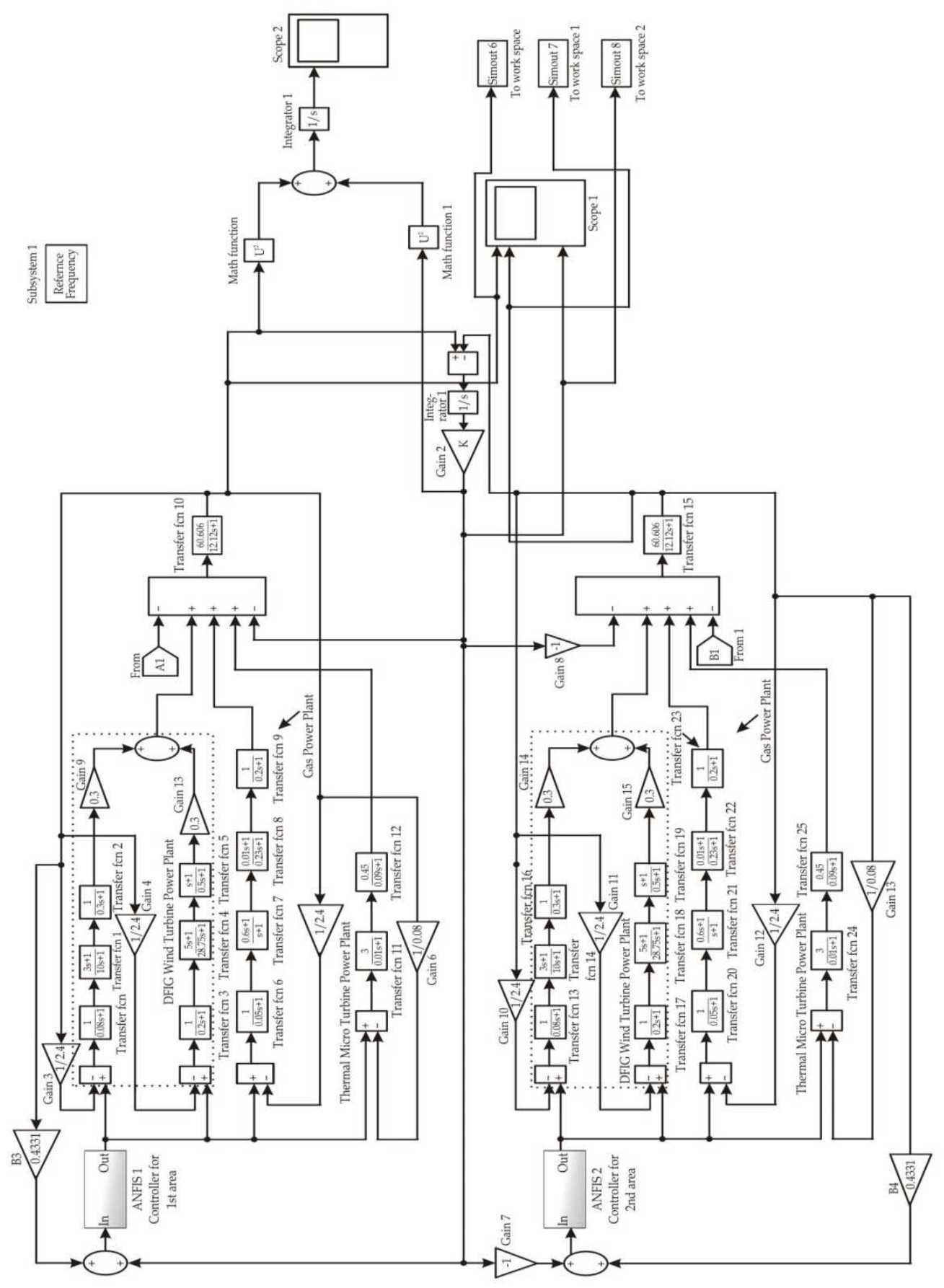

Figure 9. LFC using ANFIS-C

\section{Result Analysis}

In this section Comparative analysis of different controller analyzed in terms of Peak time (Tp), Rise Time, Ts, Peak Overshoot. 
$P I D-C$

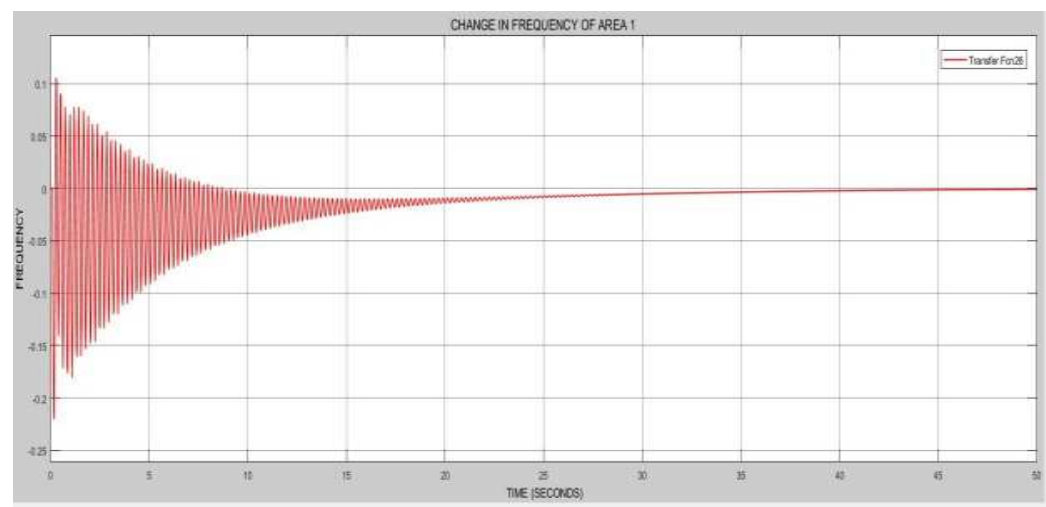

Figure 10. Change in frequency area -1 using PID-C

For area 1, Rise Time of PID-C is 10 sec. Tp of PID-C, is 30, sec. Ts of PID-C is 40, sec. Peak overshoot is $0.8 \%$. Steady state error (SSE) is $0.4 \%$.

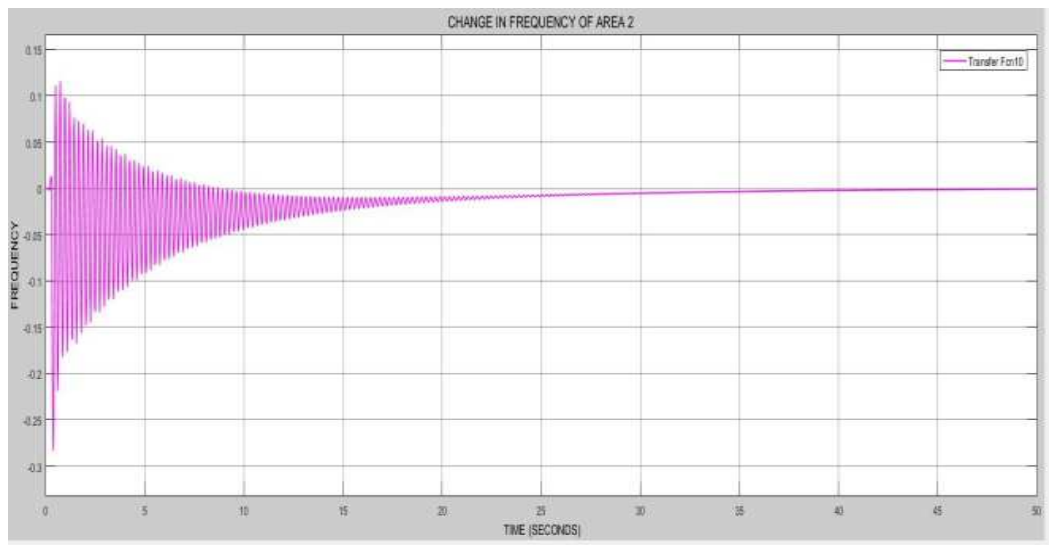

Figure 11. Change in Frequency area -2 using PID-C

For area 2, Rise Time of PID-C is $7 \mathrm{sec}$ respectively. Tp of PID-C is $30 \mathrm{sec}$. Ts of PID-C is $40 \mathrm{sec}$. Peak Overshoot is $0.6 \%$. SSE is $0.4 \%$.

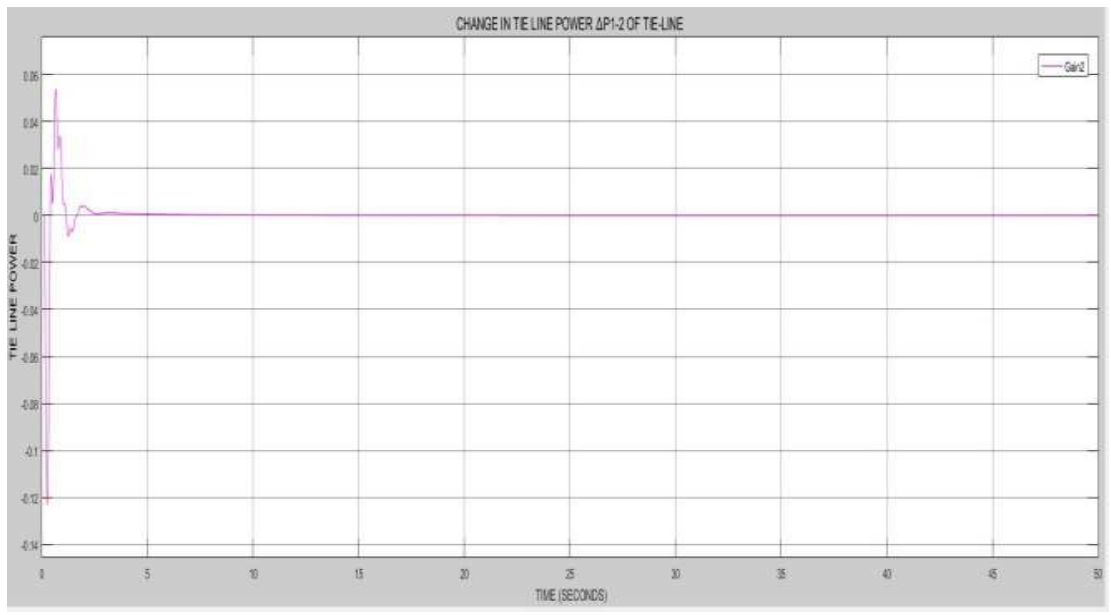

Figure 12. Tie- Line Power delta 1-2 using PID-C

For Tie lie Freq, Rise time of PID-C is $10 \mathrm{sec}$. Tp of PID-C is $30 \mathrm{sec}$. Ts of PID-C is $30 \mathrm{sec}$. Peak overshoot is $0.4 \%$. SSE is $0.4 \%$. 
$F L C$

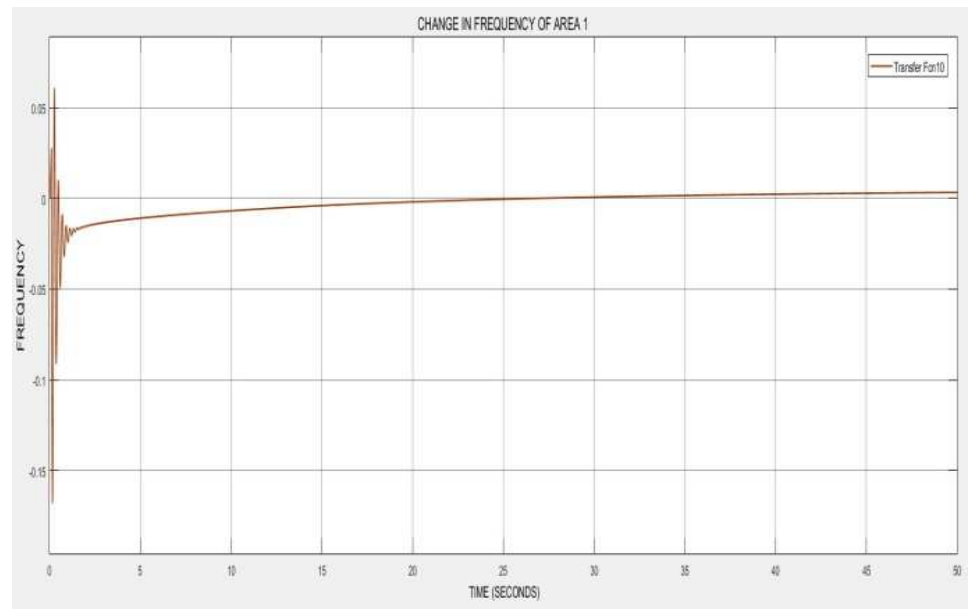

Figure 13. Change in Frequency area -1 using FLC

For area 1, Rise Time of FLC is $8 \mathrm{sec}$. Tp of FLC is $13 \mathrm{sec}$. Ts of FLC is 40. Peak Overshoot is $0.1 \%$. SSE is $0.02 \%$.

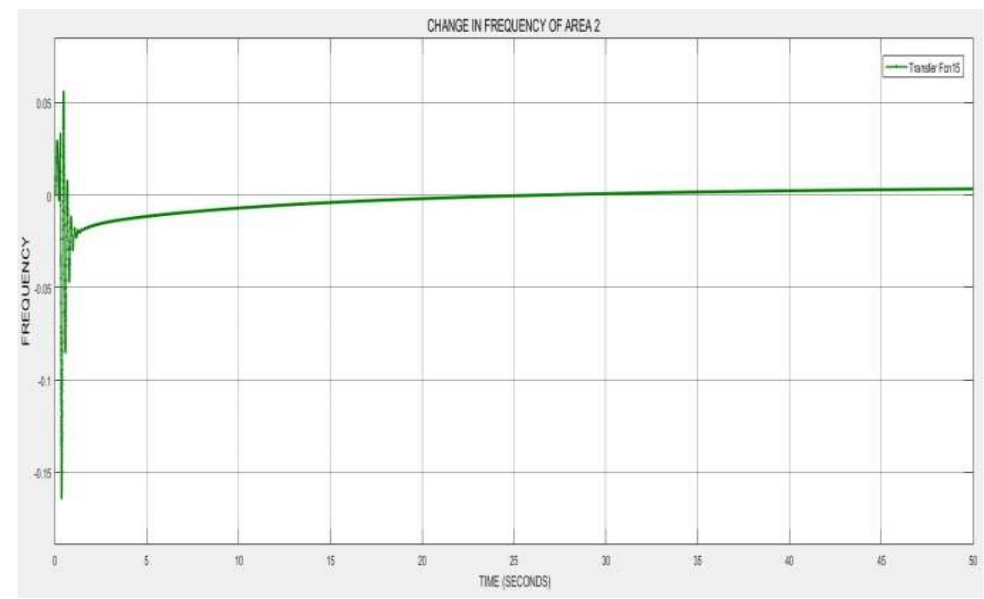

Figure 14. Change in frequency area -2 using FLC

For area 2, Rise of FLC is $10 \mathrm{sec}$ respectively. Tp of Fuzzy Logic is 18. Ts of Fuzzy Logic is $30 \mathrm{sec}$. Peak Overshoot is $0.5 \%$. SSE is $0.02 \%$.

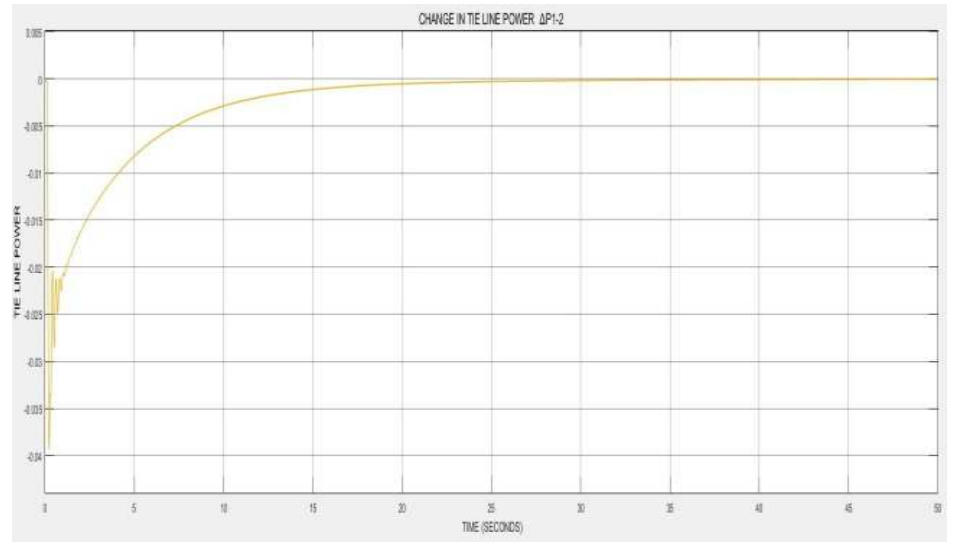

Figure 15. Tie- Line Power delta 1-2 using FLC

For Tie lie Freq, Rise time of FLC is $13 \mathrm{sec}$. Tp of FLC is $18 \mathrm{sec}$. Ts of FLC is $30 \mathrm{sec}$. Peak Overshoot is $0.01 \%$. SSE is $0.01 \%$. 
ANFIS-C

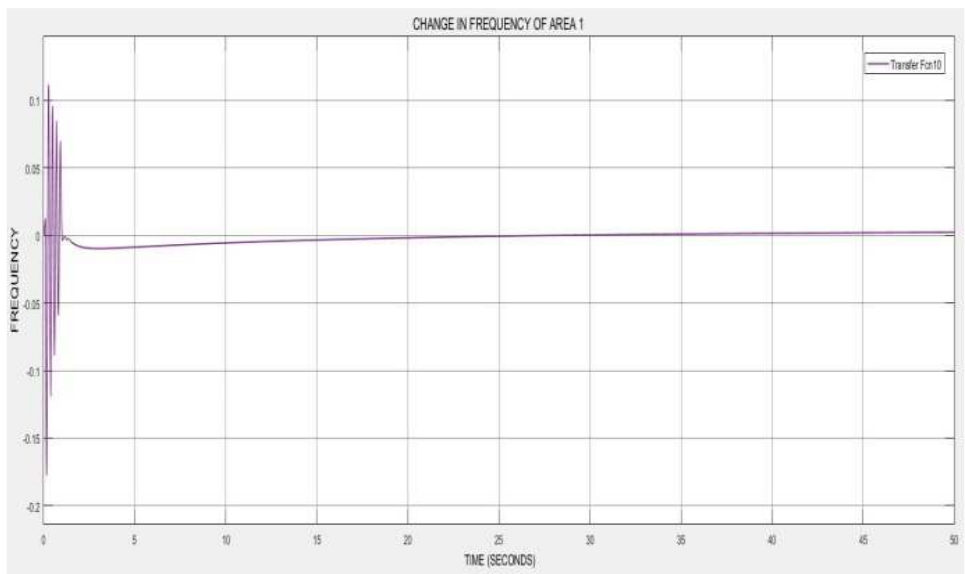

Figure 16. Change in Frequency area -1 using ANFIS-C

For area 1, Rise Time, Tp and Ts ANFIS-C is 5, $9,20 \mathrm{sec}$ respectively. Peak overshoot and SSE of ANFIS-C is $0.032 \%$ and $0.001 \%$ respectively.

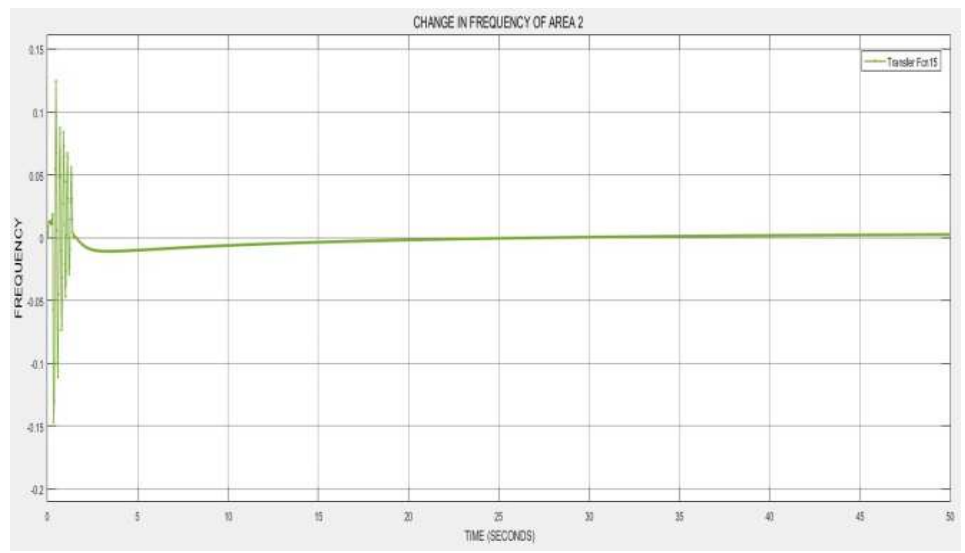

Figure 17. Change in frequency area -2 using ANFIS-C

For area 2, Rise Time, Tp and Ts ANFIS-C is 5, 13, $20 \mathrm{sec}$ respectively. Peak overshoot and SSE of ANFIS-C is $0.5 \%$ and $0.001 \%$ respectively.

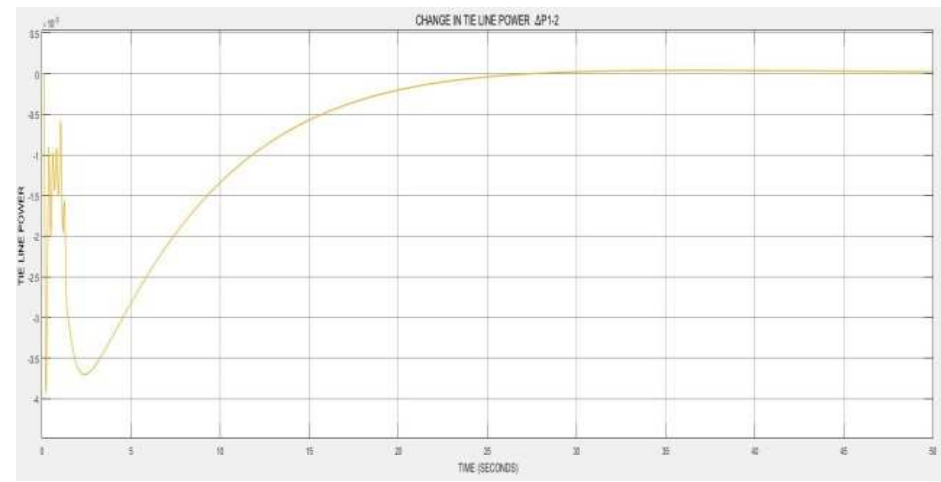

Figure 18. Tie- Line Power delta 1-2 using ANFIS-C

For Tie Line, Rise Time, Tp and Ts ANFIS-C is 7, 10,22 sec respectively. Peak overshoot and SSE of ANFIS-C is $0.01 \%$ and $0.001 \%$ respectively. 


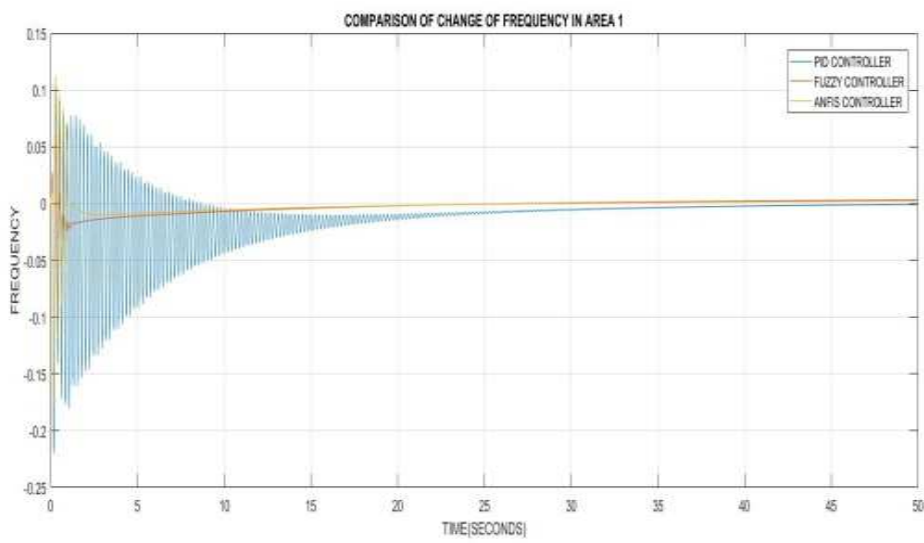

Figure 19. Comparative Analysis of Change in Frequency area -1 using PID, Fuzzy and ANFIS-C

For area 1, rise time of PID-C, FLC and ANFIS-C is 10, 8, $5 \mathrm{sec}$ respectively. Tp of PID-C, FLC and ANFIS-C is 30, 13, $9 \mathrm{sec}$ respectively. Setting time of PID-C, FLC and ANFIS-C is 40, 30, $20 \mathrm{sec}$ respectively. Percentage overshoot is $0.8 \%, 0.1 \%$ and $0.032 \%$ respectively. SSE is $0.4 \% 0.02 \%$ and $0.001 \%$ respectively.

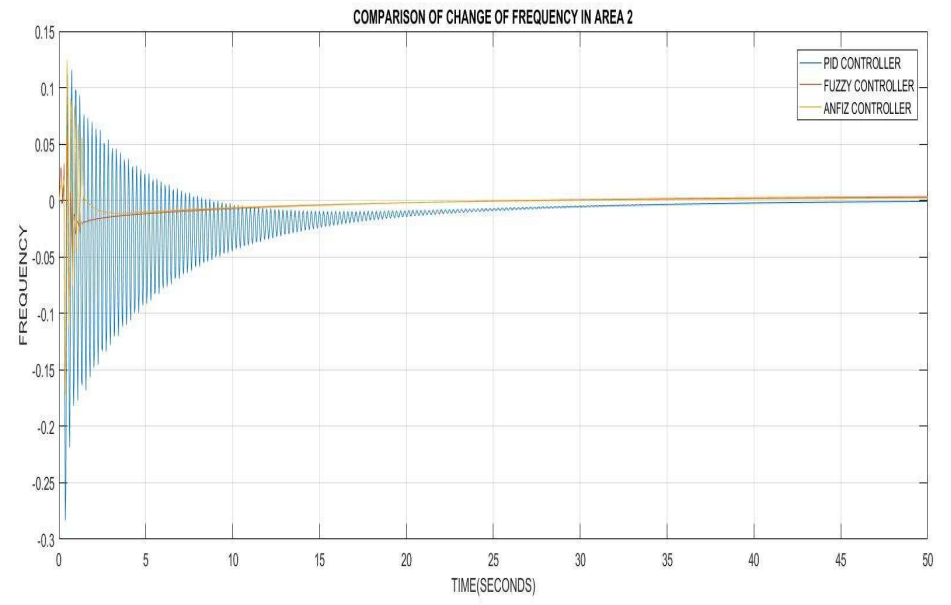

Figure 20. Comparative Analysis of Change in Frequency area -2 using PID, Fuzzy and ANFIS-C

For area 2, rise time of PID-C, FLC and ANFIS-C is 7, 10, $5 \mathrm{sec}$ respectively. Tp of PID-C, FLC and ANFIS-C is 30, 18, $13 \mathrm{sec}$ respectively. Setting time of PID-C, FLC and ANFIS-C is 40, 30, $20 \mathrm{sec}$ respectively. Percentage overshoot is $0.6 \%, 0.5 \%$ and $0.5 \%$ respectively. SSE is $0.4 \%, 0.02 \%$ and $0.001 \%$ respectively. For Tie lie frequency, rise time of PID-C, FLC and ANFIS-C is $10,13,7 \mathrm{sec}$ respectively. Tp of PID-C, FLC and ANFIS-C is 30, 18, $10 \mathrm{sec}$ respectively. Setting time of PID-C, FLC and ANFIS$\mathrm{C}$ is $30,30,22 \mathrm{sec}$ respectively.

The percentage overshoot is $0.4 \%, 0.01 \%$ and $0.01 \%$ respectively. SSE is $0.4 \%, 0.01 \%$ and $0.001 \%$ respectively. For area 1 , rise time of PID-C, FLC and ANFIS-C is 10, 8, $5 \mathrm{sec}$ respectively. Tp of PID-C, FLC and ANFIS-C is 30, 13, 9 sec respectively. Setting time of PID-C, FLC and ANFIS-C is 40, 30, $20 \mathrm{sec}$ respectively. The percentage overshoot is $0.8 \%, 0.1 \%$ and $0.032 \%$ respectively. SSE is $0.4 \% 0.02 \%$ and $0.001 \%$ respectively.

Table 2. AREA 1 Change in Freq.

\begin{tabular}{|c|l|l|l|l|}
\hline S.No. & Parameter & PID-C & FLC & ANFIS-C \\
\hline 1. & Rise Time & 10 & 8 & 5 \\
\hline 2. & Tp & 30 & 13 & 9 \\
\hline 3. & Ts & 40 & 30 & 20 \\
\hline 4. & Overshoot & $0.8 \%$ & $0.1 \%$ & $0.032 \%$ \\
\hline 5. & SSE & $0.4 \%$ & $0.02 \%$ & $0.001 \%$ \\
\hline
\end{tabular}


Table 3. AREA 2 Change in Freq.

\begin{tabular}{|l|l|l|l|l|}
\hline Sr. No. & Parameter & PID-C & FLC & ANFIS-C \\
\hline 1. & Rise Time & 7 & 10 & 5 \\
\hline 2. & Tp & 30 & 18 & 13 \\
\hline 3. & Ts & 40 & 30 & 20 \\
\hline 4. & Overshoot & $0.6 \%$ & $0.5 \%$ & $0.5 \%$ \\
\hline 5. & SSE & $0.4 \%$ & $0.002 \%$ & $0.001 \%$ \\
\hline
\end{tabular}

For area 2, rise time of PID-C, FLC and ANFIS-C is 7, 10, $5 \mathrm{sec}$ respectively. Tp of PID-C, FLC and ANFIS-C is 30, 18, 13 sec respectively. Setting time of PID-C, FLC and ANFIS-C is 40, 30, $20 \mathrm{sec}$ respectively. percentage overshoot is $0.6 \%, 0.5 \%$ and $0.5 \%$ respectively. SSE is $0.4 \%, 0.02 \%$ and $0.001 \%$ respectively.

\section{Conclusion}

Many research deals with LFC have been accounted for as of late. Still there is much space for further improvement and expansions of LFC methodologies. In this proposition ideal yield criticism controller structure strategy is proposed for LFC of reasonable power framework. Execution of proposed controller is exhibited on multi-source control framework and its dynamic reactions are contrasted and full state criticism controller. Impact of GRC on f deviation reaction is examined. Dynamic execution of framework weakens if GRC isn't fused for reasonable investigation of framework. Frequency deviation reaction of zone and generator yield control deviation reaction to $1 \%$ step burden bothers have been acquired. Yield criticism controller gives better $\mathrm{f}$ deviation reaction having generally littler pinnacle overshoot and lesser ST with zero SSE when contrasted with full state input controller reaction. The net conclusion for the research is that the rise time of PID-C, FLC and ANFIS-C is 10, 8, 5 sec respectively. Tp of PID-C, FLC and ANFIS-C is 30, 13, $9 \mathrm{sec}$ respectively. Setting time of PID-C, FLC and ANFIS-C is 40, 30, $20 \mathrm{sec}$ respectively. Percentage overshoot is $0.8 \%, 0.1 \%$ and $0.032 \%$ respectively. SSE is $0.4 \% 0.02 \%$ and $0.001 \%$ respectively. In this Paper LFC is described, further possibilities to extend this work are discussed below: Research work can be carried out with the integration of Renewable Energy Sources in the proposed Model and different constraints can be taken to study the proposed Model. Analysis of LFC on Micro-grids may be extended for further study. Different AI Techniques may be applied on the proposed model for the analysis of LFC.

\section{References}

Bhatt P., Ghoshal S.P., Roy R. 2010. Load frequency stabilization by coordinated control of thyristor controlled phase shifters and superconducting magnetic energy storage for three types of interconnected two-area power systems, International Journal Electrical Power Energy System, Vol. 32, No. 10, pp. 1111-24. https://doi.org/10.1016/j.ijepes.2010.06.009

Hameed S., Das B., Pant V. 2010, Reduced rule base self-tuning fuzzy PI controller for TCSC. International Journal of Electrical Power \& Energy Systems, Vol. 32, No. 9, pp. 1005-1013.

Ikhe A., 2013. Load frequency control for interconnected power system using different controllers, Automation, Control and Intelligent Systems, Vol. 1, No. 4, pp. 85-89

Khodabakhshian A., Golbon N. 2005. Robust LFC design for hydro power systems. In: Proceeding of IEEE CCA-2005, 28-31 August 2005, pp. 1510-1515.

Kothari M.L., Nanda J., Kothari D.P., Das D. 1989. Discrete-mode automatic generation control of two-area reheat thermal system with new area control error. IEEE Transactions on Power System, Vol. 9, No. 5, pp. 70-71. DOI: 10.1109/MPER.1989.4310715

Kocaarslan I., Cam E. 2005. Fuzzy logic controller in interconnected electrical power systems for LFC, International Journal of Electrical Power \& Energy Systems, Vol. 27, No. 8, pp. 542-549. https://doi.org/10.1016/j.ijepes.2005.06.003

Melin P., Castillo O. 2003, New method for adaptive model-based control of nonlinear plants using type-2 fuzzy logic and neural networks, Proceedings of IEEE FUZZ Conference, St. Louis, USA; 2003. pp. 420-25.

Nanda J. and Mangla A. 2004. Automatic generation control of an interconnected hydro-thermal system using conventional integral and fuzzy logic controller, Proceedings of the 2004 IEEE International Conference on Electric Utility Deregulation, Restructuring and Power Technologies, 2004. (DRPT 2004), Vol. 1. DOI: 10.1109/DRPT.2004.1338524

Panda G., Panda S., Ardil C. 2009, Hybrid neuro fuzzy approach for automatic generation control of two-area interconnected power system. International Journal of Computer Intelligence, Vol. 5, No. 1, pp. 80-84.

Sahu B.K., Pati S., Mohanty P.K. and Panda S. 2015. Teaching learning based optimization algorithm based fuzzy PID controller for automatic generation control of multi area power system, Applied Soft Computing, Vol. 27, pp. 240-249. https://doi.org/10.1016/j.asoc.2014.11.027

Sepulveda R., Castillo O., Melin P., Rodriguez-Diaz A., Montiel O. 2005, Handling uncertainty in controllers using type-2 fuzzy logic, Proceedings of IEEE Fuzzy Conference, Reno, USA; 2005. pp. 248-53.

Sharma D. and Yadav N.K. 2019. Lion algorithm with levy update: Load frequency controlling scheme for two-area interconnected multi-source power system, Transaction of the Institute of Measurement and Control, Vol. 41, No. 14, pp. 4084-4099. 
Sharma D. and Yadav N.K. 2018. Some Aspects of Automatic generation control, IOSR Journal of Engineering, Vol. 8, No. 7, pp. 86-99.

Sharma D. and Yadav N.K. 2017. A comprehensive review on load frequency control, International Journal of Emerging Technology and Advanced Engineering, Vol. 7, No. 8, pp. 499-504.

Sharma D. 2020. Load frequency control: A literature review, International Journal of Scientific and Technology Research, Vol. 9 , No. 2, pp. 6421-6437.

Sharma D. and Yadav N.K. 2020. LFOPI controller: a fractional order PI controller based load frequency control in two area multi source interconnected power system, Data Technologies and Applications, Vol. 54 No. 3, pp. 323-342. https://doi.org/10.1108/DTA-08-2019-0126

Shayeghi H., Shayanfar H.A. 2006, Application of ANN technique based on $\mu$-synthesis to LFC of interconnected power system, International Journal of Electrical Power \& Energy Systems, Vol. 28, No. 7, pp. 503-511. https://doi.org/10.1016/j.ijepes.2006.02.012

Stankovic A.M., Tadmor G., Sakharuk T.A. 1998. On robust control analysis and design for load frequency regulation. IEEE Transactions on Power Systems, Vol. 13, No. 2, pp. 449-455.

Usman A., Divakar B.P. 2012, Simulation study of LFC of single and two area systems, IEEE Global Humanitarian Technology Conference, pp. 214-219.

Zribi M., Al-Rashed M., Alrifai M. 2005, Adaptive decentralized LFC of multi-area power systems, International Journal of Electrical Power \& Energy Systems, Vol. 27, No. 8, pp. 575-583. https://doi.org/10.1016/j.ijepes.2005.08.013

\section{Biographical notes}

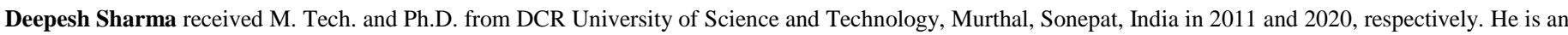

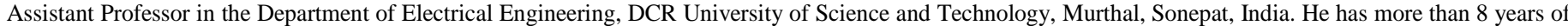

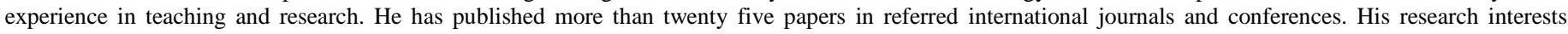
include power system restructuring, power system optimization \& control, renewable energy and smart grid. 